\title{
Apolipoprotein E4 Genotype and Depressive Symptoms as Risk Factors for Dementia in an Older Korean Population
}

\author{
Jae-Min Kim \\ Seon-Young Kim \\ Kyung-Yeol Bae \\ Sung-Wan Kim \\ II-Seon Shin ${ }^{\bowtie}$ \\ Su-Jin Yang \\ Young-Heon Song \\ Jin-Sang Yoon
}

Department of Psychiatry,

Chonnam National University

Medical School, Gwangju, Korea

\section{$\triangle$ Correspondence}

Il-Seon Shin, MD, PhD

Department of Psychiatry, Chonnam National University

Medical School,

5 Hak-dong, Dong-gu, Gwangju 501-757, Korea

Tel +82-61-379-7762

Fax +82-62-225-2351

E-mailisshin@chonnam.ac.kr

(a) This is an Open Access article distributed under the terms of the Creative Commons Attribution Non-Commercial License (http://creativecommons.org/licenses/by-nc/3.0) which permits unrestricted non-commercial use, distribution, and reproduction in any medium, provided the original work is properly cited.
Objective Growing evidence suggests the separate associations of apolipoprotein E e4 allele (apo E4) and depression with incident dementia. This study investigated the separate and combined effects of apo E4 and depression on the incidence of dementia in both men and women.

Methods Of 625 elderly without dementia at baseline, 518 (83\%) were followed over a 2.4year period and were assessed clinically for incident dementia. The apo E polymorphism was ascertained, and depression was identified using the Korean version of the Geriatric Depression Scale (KGDS). Covariates included age, gender, education, disability, alcohol history, physical activity, and vascular risk factors.

Results The incidence of dementia was significantly higher in elderly Koreans with both apo E4 and depression compared to those without both factors [adjusted odds ratio $(95 \% \mathrm{CI})=5.85$ (1.77-19.38)]. This interaction was significant in men $(p=0.049)$, but not in women $(p=0.354)$.

Conclusion Depressed elderly people are at great risk for incident dementia in the presence of apo E4. Potential gender differences require further evaluation.

Psychiatry Investig 2010;7:135-140

Key Words Apolipoprotein E, Depression, Gene association study, Dementia, Alzheimer's disease.

Received: September 11, 2009 Revised: February 25, 2010 Accepted: February 25, 2010

Available online: May 4, 2010

\section{Introduction}

The apolipoprotein E e4 allele (apo E4) is a well-established genetic risk factor for Alzheimer's disease (AD). ${ }^{1}$ Prospective studies have reported that depression is associated with subsequent dementia, including $\mathrm{AD},{ }^{2-4}$ although some exceptions have been reported. ${ }^{5} \mathrm{~A}$ review article stated that depression might be a prodromal phenomenon in the course of dementia. ${ }^{6}$ Furthermore, only the most severe syndromes and cases of depression were risk factors for dementia in cohort studies in China and the United Kingdom (UK). ${ }^{7}$ A recent meta-analysis of 11 cohort studies suggested that depression is an independent risk factor for AD. ${ }^{8}$ In addition, apo E4 has been found to be associated with various vascular risks and diseases, ${ }^{9,10}$ and it therefore may be associated with depression in late life, as age is closely related to vascular factors. ${ }^{11}$ We hypothesized that apo E4 and depression have a combined effect on dementia. In the recently published Honolulu-Asia Aging Study, the individuals with apo E4 and depressive symptoms at baseline had a 7-fold greater risk of dementia after 6 years of follow-up compared with those with neither apo E4 nor depression. ${ }^{12}$

As this cohort included only men, the hypothesis has yet to be examined in women. Using data from a prospective community study of an older Korean population, this study investigated the separate and combined effects of apo E4 and depression on the incidence of dementia in both men and women. 


\section{Methods}

\section{Study outline and participants}

A prospective community survey of late-life psychiatric morbidity was carried out in Gwangju, South Korea from 2001 to 2003, in collaboration with the 10/66 International Dementia Research Program in Developing Countries. ${ }^{13}$ The study design has been described in several publications. ${ }^{14,15}$ At baseline, all community residents aged 65 years or over within two geographic catchments were systematically identified from national registration lists and were approached to participate. A range of assessment scales and diagnostic instruments was administered, and blood samples were obtained. Attempts were made to reassess all participants two years later (mean interval 2.4 \pm 0.3 years), when almost identical procedures to those at baseline were performed. All participants gave formal written informed consent at each examination. This study was approved by the Chonnam National University Hospital Institutional Review Board.

\section{Ascertainment of dementia}

Identical assessments for dementia were carried out at baseline and follow-up, including the Mini-Mental State Examination, ${ }^{16}$ Instrumental Activities of Daily Living Scale, ${ }^{17}$ Clinical Dementia Rating Scale, ${ }^{18}$ collateral information on past history, and a full physical and neurological examination. A committee of senior clinical researchers assigned consensus diagnoses, using standard criteria for dementia, ${ }^{19} \mathrm{AD},{ }^{20}$ and vascular dementia. ${ }^{21}$ These were applied blindly to all other clinical information, including the results of the blood assays, which were the focus of this analysis.

\section{Apo E genotyping}

Blood was drawn from the participants. DNA was amplified using the polymerase chain reaction, and the apo E genotype was determined, using standard reported procedures, ${ }^{22}$ by a laboratory specialist blind to the participants' characteristics, and the results were categorized according to the presence or absence of apo E4.

\section{Depression}

Depression was evaluated using the Korean Geriatric Depression Scale (KGDS) ${ }^{23}$ It comprises 30 questions, principally items from the Geriatric Depression $\mathrm{Scale}^{24}$ supplemented by others from the Beck Depression Inventory, ${ }^{25}$ Self-rating Depression Scale, ${ }^{26}$ Minnesota Multiphasic Personality Inventory Depression Scale, ${ }^{27}$ and Center for Epidemiologic Studies Depression Scale. ${ }^{28}$

Its screening properties have been assessed previously against formal psychiatric diagnoses, and a 13/14 cut-off value was found to have an optimal balance of sensitivity (74\%) and specificity $(72 \%)$ for clinically significant depression. ${ }^{23}$

\section{Other covariates at baseline}

Demographic data on age, gender, and education were recorded. Disability was measured using the World Health Organization Disability Assessment Schedule II (WHODAS II). ${ }^{29}$ Alcohol history (high alcohol consumption over the previous 3 months was defined as $>14$ drinks/week for men, $>7$ drinks/ week for women) and daily physical activity (low activity was defined as a predominantly sedentary lifestyle) were ascertained. For vascular risk factors and disorders, a summary risk score was calculated by summing self-reported disorders (stroke, heart disease, hypertension, and diabetes), measured obesity (body mass index $>25 \mathrm{~kg} / \mathrm{m}^{2}$ ), and hypercholesterolemia (fasting cholesterol $>200 \mathrm{mg} / \mathrm{dL}$ ).

\section{Statistical analysis}

SPSS 12.0 software was used. For the analysis presented here, participants with dementia at baseline were excluded. Incident dementia was the dependent variable for all analyses. Baseline characteristics of the participants were compared by incident dementia status using the t-test, $\chi^{2}$ test, or Mann-Whitney U-test as appropriate. To assess the individual associations of apo E4 and depression with incident dementia, logistic regression analyses were conducted. To assess the combined effect, participants were categorized into four subgroups according to the presence or absence of apo E4 and baseline depression. The associations of apo E4 and depression with incident dementia were investigated using logistic regression analyses, treating the 'absent apo E4-absent depression' subgroup as the reference category before and after adjustment. The interaction between apo E4 and depression was evaluated by including an interaction term (apo E4×depression) in the models.

\section{Results}

\section{Participant characteristics}

Of the 732 participants at baseline, 625 did not have dementia. Of these, 518 (83\%) completed all evaluations at follow-up and comprised the sample for this analysis. Participants lost to follow-up ( $\mathrm{n}=107)$ did not differ significantly compared to the analyzed sample for any baseline variable (data not shown). In the analyzed sample $(\mathrm{n}=518)$, incident cases of dementia were identified in 45 participants (8.7\%): 34 (6.6\%) AD, seven $(1.4 \%)$ vascular dementia, and four 'other' dementia $(0.8 \%)$. The baseline characteristics are described and compared by incident dementia status in Table 1. Incident dementia was also significantly predicted by older age, lower education, more severe disability, and less physical activity.

\section{Separate effects of apo E4 and baseline depression on incident dementia}

The individual associations of apo E4 and depression with incident dementia are summarized in Table 2. In the unadjust- 
Table 1. Baseline characteristics by incident dementia status

\begin{tabular}{|c|c|c|c|c|c|}
\hline & $\begin{array}{c}\text { Total sample } \\
(\mathrm{N}=518)\end{array}$ & $\begin{array}{c}\text { No incident dementia } \\
(\mathrm{N}=473)\end{array}$ & $\begin{array}{c}\text { Incident dementia } \\
(\mathrm{N}=45)\end{array}$ & $\begin{array}{l}\text { Statistical } \\
\text { coefficient }\end{array}$ & p-value* \\
\hline Age, mean $(\mathrm{SD})$ years & $71.8(5.1)$ & $71.6(4.9)$ & $74.3(5.7)$ & $\mathrm{t}=-3.494$ & 0.001 \\
\hline Female gender, $\mathrm{N}(\%)$ & $282(54.4)$ & $254(53.7)$ & $28(62.2)$ & $\chi^{2}=1.203$ & 0.273 \\
\hline Education, median (IQR) years & $2(0-6)$ & $3(0-6)$ & $0(0-2)$ & $Z=-3.973$ & $<0.001$ \\
\hline WHODAS II, median (IQR) score & $2.2(0-7)$ & $2.1(0-6)$ & $5.4(1-12)$ & $Z=-3.304$ & 0.001 \\
\hline High alcohol intake, $\mathrm{N}(\%)$ & $155(29.9)$ & $141(29.8)$ & $14(31.1)$ & $\chi^{2}=0.033$ & 0.855 \\
\hline Low physical activity, $\mathrm{N}(\%)$ & $142(27.4)$ & $118(24.9)$ & $24(53.3)$ & $\chi^{2}=16.64$ & $<0.001$ \\
\hline Vascular risk score, median (IQR) score & $1(0-2)$ & $1(0-2)$ & $1(1-2)$ & $Z=0.121$ & 0.121 \\
\hline
\end{tabular}

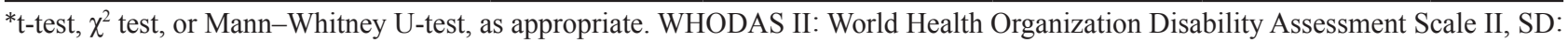
standard deviation, IQR: inter-quartile range

Table 2. Separate associations of the apolipoprotein E e4 allele (apo E4) and depression (Korean version of the Geriatric Depression Scale, scores $>13$ ) with incident dementia

\begin{tabular}{lccccc}
\hline & Total sample & No incident dementia & Incident dementia & \multicolumn{2}{c}{ Odds ratio (95\% CI) } \\
\cline { 5 - 7 } & $(\mathrm{N}=518)$ & $(\mathrm{N}=473)$ & $(\mathrm{N}=45)$ & Unadjusted & Adjusted \\
\hline Apo E4 allele, $\mathrm{N}(\%)$ & $89(17.2)$ & $74(15.6)$ & $14(31.1)$ & $2.44(1.24-4.80)$ & $1.75(1.21-2.52)$ \\
Depression, $\mathrm{N}(\%)$ & $108(20.8)$ & $92(19.5)$ & $16(35.6)$ & $2.29(1.19-4.38)$ & $1.33(0.62-2.84)$ \\
\hline
\end{tabular}

Adjusted for age, education, disability, and physical activity. CI: confidence interval

Table 3. Combined associations of apolipoprotein E e4 allele (apo E4) and depression (Korean version of the Geriatric Depression Scale >13) with incident dementia

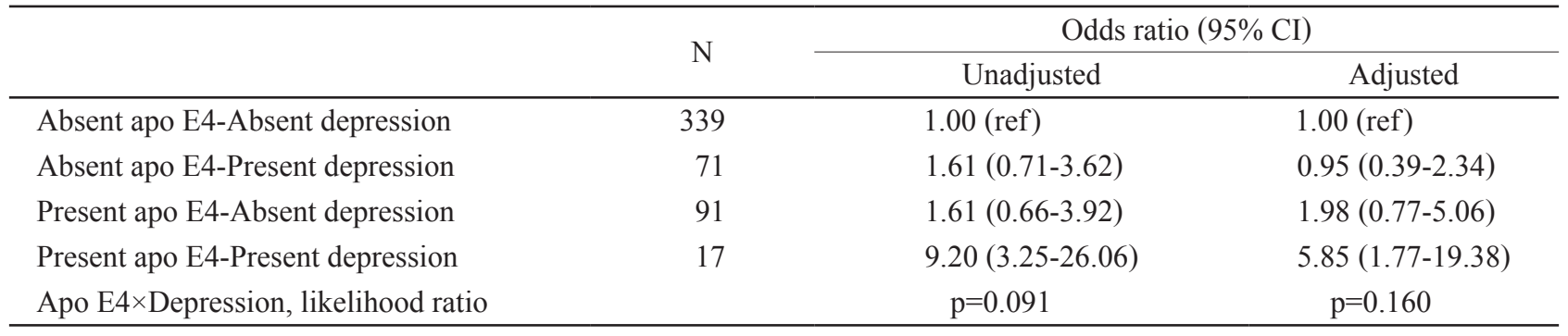

Adjusted for age, education, disability, and physical activity. CI: confidence interval

ed analyses, apo E4 and baseline depression were significantly associated with incident dementia. The strengths of the associations between apo E4 and incident dementia remained significant in the adjusted models, whereas that between baseline depression and incident dementia fell below significance. After further adjusting for the vascular risk score, the strengths of the associations fell slightly, but not substantially, as the odd ratios $[95 \%$ confidence intervals (CIs)] for the associations of apo E4 and depression were 1.74 (1.21-2.51) and 1.30 (0.61-2.79), respectively.

\section{Combined effects of apo E4 and baseline depression on incident dementia}

The univariate associations with incident dementia according to the presence or absence of apo E4 and baseline depression are summarized in the second column of Table 3. Compared to the 'absent apo E4-absent depression' subgroup, the 'present apo E4-present depression' subgroup had a 9.2-fold greater risk of incident dementia. The multivariate associa- tions with incident dementia and the interaction between apo E4 and depression in the models are summarized in the third column in Table 3. After adjusting for baseline age, education, disability, and physical activity, incident dementia remained significantly increased in the 'present apo E4-present depression' subgroup, although the strength of the association was weakened substantially. The associations in the other subgroups did not reach statistical significance. The interaction terms between apo E4 and depression were borderline significant before adjustment and fell below significance after adjustment. Further adjustment for the vascular risk score in all models had no substantial effect on the results (data not shown).

\section{Additional analyses}

In the analyses stratified by gender using the same models, the adjusted odds ratios $(95 \% \mathrm{CI})$ for incident dementia in the 'present apo E4-present depression' subgroup compared to the 'absent apo E4-absent depression' reference subgroup were 17.51 (2.82-108.6) and 4.57 (1.31-15.98) in men and women, 
respectively. The interaction terms between apo E4 and depression on incident dementia in the full adjusted model were significant in men $(\mathrm{p}=0.049)$, but not in women $(\mathrm{p}=0.354)$. In an analysis with $\mathrm{AD}$ as the dependent variable, the adjusted odd ratios $(95 \% \mathrm{CI})$ for incident dementia in the 'present apo E4present depression' subgroup compared to the 'absent apo E4absent depression' reference subgroup was 4.78 (1.59-14.40). The interaction terms between apo E4 and depression on incident $\mathrm{AD}$ in the full adjusted model was borderline significant $(\mathrm{p}=0.087)$.

\section{Discussion}

The principal finding of this prospective study of community elderly was that the synergistic interaction between apo E4 and depression has an effect on incident dementia. The incidence of dementia was significantly higher in the "present apo E4-present depression' subgroup compared to the 'absent apo E4-absent depression' subgroup. This interaction was significant in men, but not in women. Similar interactions were found for $\mathrm{AD}$ as another independent variable.

The strengths of this study were that the design was prospective, the dementia diagnoses were kept blind with respect to other information and followed standard criteria, the analyses considered various potential confounding factors, and the follow-up rate was reasonable and not different with respect to the exposures of interest. Limitations of the study were that the sample was relatively small for further stratification by gender and dementia subtypes, incident dementia was evaluated over a relatively short period, and accurate timing of the onset of dementia was not possible. The annual incidence of dementia in this sample was about $3.6 \%$. This is comparable with the $3-4 \%$ range reported in some studies, ${ }^{30,31}$ but higher than the $1-2 \%$ range suggested by others. ${ }^{3,12}$ The relatively high prevalence of dementia observed at baseline ${ }^{32}$ does not suggest that the observed high incidence was accounted for by previously missed cases. Another limitation was that the depressive participants categorized by the KGDS cutoff might have had moderate levels of depression, and the results may not be generalizable to secondary care clinical samples with more severe syndromes. In addition, the baseline depression was unlikely to reflect full syndrome trajectories, and therefore may have missed changes in depressive status that occurred between the examination points.

Apo E4 was an independent risk factor for incident dementia in this study. Apo E4 is an established risk factor for AD based on numerous studies of various ethnicities and populations. ${ }^{1}$ Apo E4 is also associated with cognitive decline in the elderly with normal cognition, which is salient to the findings of our study. ${ }^{33}$

Previous studies of the associations between an earlier history of depression and later dementia have generally found sig- nificant results ${ }^{8,34,35}$ However, the associations between baseline depression and incident dementia in circumscribed cohorts have been controversial: some studies reported significant associations, ${ }^{2,36}$ while other studies found significant associations only in men, ${ }^{3,4}$ and yet other studies have found no significant results. ${ }^{5,30}$ Differences in study design, such as the followup duration, participant characteristics, confounding factors considered, and methods of identifying depression, may explain the conflicting results. In our study based on self-report, baseline depression was significantly associated with incident dementia in the unadjusted analyses, but not after adjusting for the covariates. It has been suggested that vascular diseases are shared risk factors for depression and dementia. ${ }^{37}$ In our study, however, the association between baseline depression and incident dementia was explained by age, education, disability, and physical inactivity, rather than by vascular risk factors. Previous studies also reported that the associations of depression with AD or mild cognitive impairment were independent of vascular risk factors. ${ }^{4,38}$

Apo E4 not only increased the risk of dementia, but also modified the effects of other risk factors for dementia. The association between smaller head circumference and incident AD was particularly significant in the presence of apo E4. ${ }^{39}$ The rate of cognitive decline associated with vascular diseases was increased by the presence of apo E4. ${ }^{40}$ In keeping with these findings, one can also postulate that depression interacts with apo E4 in the incidence of dementia, although this has rarely been tested. The recently published Honolulu-Asia Aging Study was the first to test this hypothesis. That study found that elderly people with both depressive symptoms and apo E4 at baseline had a markedly increased risk of dementia. ${ }^{12}$ Similar results have been found in a few recent studies, although the dependent variable was not dementia. In a cohort of elderly persons with normal cognitive function, a synergistic interaction between depression and apo E4 had an effect on the incidence of mild cognitive impairment. ${ }^{41}$ In another cohort with cognitively normal elders, the influence of depressive sympto$\mathrm{ms}$ on cognitive decline was greater among individuals with apo E4. ${ }^{42}$ These synergistic effects might be explained at neuropathological levels. The apo E4 accelerated the deposition of amyloid in the brain, one of the pathognomonic substances of AD. Depression could also lead to stress-induced neuroplastic changes in specific neural circuits, including the hippocampus, which is very important for memory function. ${ }^{43}$ Therefore, the individuals with both apo E4 and depression might be particularly susceptible to developing dementia. Another plausible mechanism is that apo E4 could be a shared genetic factor for both depression and dementia. Apo E4 has been associated with various cardiovascular diseases, ${ }^{9}$ which are closely related to both depression and dementia. ${ }^{37}$ In our study, however, the interaction between depression and apo E4 in incident dementia was not substantially explained by vascular risk factors. 
Depression was significantly associated with dementia only in men, and not in women in a few studies, ${ }^{3,4}$ whereas most other studies found no gender differences. ${ }^{8}$ We also found no gender differences in the individual associations between depression and incident dementia. With respect to the gender effects on the interaction between apo E4 and depression on incident dementia, the only previous study to examine this issue could not test the hypothesis because that study included only male participants. ${ }^{12}$ Our study allowed testing of this hypothesis because the study sample consisted of both men and women. Consistent with previous results, the interaction was particularly significant in men and was not significant in women. Gender differences in the neurobiology of depression ${ }^{44}$ may explain this finding. However, one should be cautious when drawing conclusions from this finding, because the previous studies reporting interactions between apo $\mathrm{E} 4$ and depression in mild cognitive impairment or cognitive decline have not found gender differences. ${ }^{41,42}$ Further replication studies are needed.

Our findings suggest that elderly people with depressive symptoms are at greater risk for incident dementia in the presence of apo E4. Elderly individuals with both apo E4 and depression should be monitored more carefully for early symptoms of dementia. Given that the genetic factor cannot be modified and that depression usually responds to pharmacological and psychological management, depression should be treated appropriately in those with both susceptibility factors. Although the theme of this study is very important and relevant from a public health perspective, it has rarely been studied. Therefore, the study should be replicated in various populations. The biological mechanisms underlying the interaction between apo E4 and depression have yet to be determined. In addition, possible gender differences in the interaction require further evaluation.

\section{-Acknowledgments}

This research was supported by a grant from the Korea Health $21 \mathrm{R} \& D$, Ministry of Health and Welfare, Republic of Korea (A050047).

\section{REFERENCES}

1. Bertram L, Tanzi RE. Thirty years of Alzheimer's disease genetics: the implications of systematic meta-analyses. Nat Rev Neurosci 2008;9:768-778.

2. Pálsson S, Aevarsson O, Skoog I. Depression, cerebral atrophy, cognitive performance and incidence of dementia. Population study of 85-yearolds. Br J Psychiatry 1999;174:249-253.

3. Fuhrer R, Dufouil C, Dartigues JF; PAQUID Study. Exploring sex differences in the relationship between depressive symptoms and dementia incidence: prospective results from the PAQUID Study. J Am Geriatr Soc 2003;51:1055-1063.

4. Dal Forno G, Palermo MT, Donohue JE, Karagiozis H, Zonderman AB, Kawas CH. Depressive symptoms, sex, and risk for Alzheimer's disease. Ann Neurol 2005;57:381-387.

5. Ganguli M, Du Y, Dodge HH, Ratcliff GG, Chang CC. Depressive symptoms and cognitive decline in late life: a prospective epidemiological study. Arch Gen Psychiatry 2006;63:153-160.
6. Brown EL, Raue P, Halpert KD, Adams S, Titler MG. Detection of depression in older adults with dementia. J Gerontol Nurs 2009;35:11-15.

7. Chen R, Hu Z, Wei L, Qin X, McCracken C, Copeland JR. Severity of depression and risk for subsequent dementia: cohort studies in China and the UK. Br J Psychiatry 2008;193:373-377.

8. Ownby RL, Crocco E, Acevedo A, John V, Loewenstein D. Depression and risk for Alzheimer disease: systematic review, meta-analysis, and metaregression analysis. Arch Gen Psychiatry 2006;63:530-538.

9. McCarron MO, Delong D, Alberts MJ. APOE genotype as a risk factor for ischemic cerebrovascular disease: a meta-analysis. Neurology 1999; 53:1308-1311.

10. Nebes RD, Vora IJ, Meltzer CC, Fukui MB, Williams RL, Kamboh MI, et al. Relationship of deep white matter hyperintensities and apolipoprotein E genotype to depressive symptoms in older adults without clinical depression. Am J Psychiatry 2001;158:878-884.

11. Alexopoulos GS, Meyers BS, Young RC, Capbell S, Silbersweig D. Charlson M. 'Vascular depression' hypothesis. Arch Gen Psychiatry 1997;54:915-922.

12. Irie F, Masaki KH, Petrovitch H, Abbott RD, Ross GW, Taaffe DR, et al. Apolipoprotein E epsilon4 allele genotype and the effect of depressive symptoms on the risk of dementia in men: the Honolulu-Asia Aging Study. Arch Gen Psychiatry 2008;65:906-912.

13. Prince M, Acosta D, Chiu H, Scazufca M, Varghese M; 10/66 Dementia Research Group. Dementia diagnosis in developing countries: a croSs-cultural validation study. Lancet 2003;361:909-917.

14. Kim JM, Stewart R, Kim SW, Yang SJ, Shin IS, Kim YH, et al. Interactions between life stressors and susceptibility genes (5-HTTLPR and BDNF) on depression in Korean elders. Biol Psychiatry 2007;62:423428.

15. Kim JM, Stewart R, Kim SW, Shin IS, Yang SJ, Shin HY, et al. Changes in folate, vitamin B12, and homocysteine associated with incident dementia. J Neurol Neurosurg Psychiatry 2008;79:864-868.

16. Park JH, Kwon YC. Modification of the mini-mental state examination for use in the elderly in a non-western society: Part I. Development of Korean version of Mini-Mental State Examination. Int J Geriatr Psychiatry 1990;5:381-387.

17. Lawton MP, Brody EM. Assessment of older people: self-maintaining and instrumental activities of daily living. Gerontologist 1969;9:179-186.

18. Hughes CP, Berg L, Danziger WL, Coben LA, Martin RL. A new clinical scale for the staging of dementia. Br J Psychiatry 1982;140:566-572.

19. American Psychiatric Association. Diagnostic and statistical manual of mental disorder. 4th ed. Washington, DC: American Psychiatric Press; 1994.

20. McKhann G, Drachman D, Folstein M, Katzman R, Price D, Stadlan EM. Clinical diagnosis of Alzheimer's disease: report of the NINCDSADRDA Work Group under the auspices of Department of Health and Human Services Task Force on Alzheimer's Disease. Neurology 1984; 34:939-944.

21. Roman GC, Tatemichi TK, Erkinjuntti T, Cummings JL, Masdeu JC, Garcia JH, et al. Vascular dementia: diagnostic criteria for research studies. Report of the NINDS-AIREN International Workshop. Neurology 1993:43:250-260.

22. Zivelin A, Rosenberg N, Peretz H, Amit Y, Kornbrot N, Seligsohn U. Improved method for genotyping apolipoprotein E polymorphins by a PCR-based assay simultaneously utilizing two distinct restriction enzymes. Clin Chem 1997;43:1657-1659.

23. Jung IK, Kwak DI, Joe SH, Lee HS. A study of standardization of Korean Form of Geriatric Depression Scale (KGDS). J Korean Geriatr Psychiatry 1997;1:61-72.

24. Yesavage JA, Brink TL, Rose TL, Lum O, Huang V, Adey M, et al. Development and validation of a geriatric depression scale: a preliminary report. J Psychiatr Res 1982-1983;17:37-49.

25. Beck AT, Ward CH, Mendelson M, Mock J, Erbaugh J. An inventory for measuring depression. Arch Gen Psychiatry 1961;4:561-571. 
26. Zung WW. A self-rating depression scale. Arch Gen Psychiatry 1965; 12:63-70.

27. Hathaway SR, McKinley JC. The Minnesota Multiphasic Personality Inventory. Rev ed. Minneapolis, MN: University of Minnesota Press; 1943.

28. Radloff LS, Teri L. Use of the Center for Epidemiological Studiesdepression scale with older adults. Clin Gerontol 1986;5:119-137.

29. Kim JM, Stewart R, Glozier N, Prince M, Kim SW, Yang SJ, et al. Physical health, depression and cognitive function as correlates of disability in an older Korean population. Int J Geriatr Psychiatry 2005;20:160167.

30. Chen P, Ganguli M, Mulsant BH, DeKosky ST. The temporal relationship between depressive symptoms and dementia: a community-based prospective study. Arch Gen Psychiatry 1999;56:261-266.

31. Podewils LJ, Guallar E, Kuller LH, Fried LP, Lopez OL, Carlson M, et al. Physical activity, APOE genotype, and dementia risk: findings from the Cardiovascular Health Cognition Study. Am J Epidemiol 2005; 161:639-651.

32. Kim JM, Stewart R, Shin IS, Jung JS, Yoon JS. Assessment of association between mitochondrial aldehyde dehydrogenase polymorphism and Alzheimer's disease in an older Korean population. Neurobiol Aging 2004;25:295-301.

33. Brayne C, Harrington CR, Wischik CM, Huppert FA, Chi LY, Xuereb $\mathrm{JH}$, et al. Apolipoprotein E genotype in the prediction of cognitive decline and dementia in a prospectively studied elderly population. Dementia 1996;7:169-174.

34. Lindsay J, Laurin D, Verreault R, Hébert R, Helliwell B, Hill GB, et al. Risk factors for Alzheimer's disease: a prospective analysis from the Canadian Study of Health and Aging. Am J Epidemiol 2002;156:445453.

35. Andersen K, Lolk A, Kragh-Sørensen P, Petersen NE, Green A. De- pression and the risk of Alzheimer disease. Epidemiology 2005;16: 233-238.

36. Devanand DP, Sano M, Tang MX, Taylor S, Gurland BJ, Wilder D, et al. Depressed mood and the incidence of Alzheimer's disease in the elderly living in the community. Arch Gen Psychiatry 1996;53:175-182.

37. Kim JM, Stewart R, Shin IS, Yoon JS. Vascular disease/risk and latelife depression in a Korean community population. Br J Psychiatry 2004; 185:102-107.

38. Barnes DE, Alexopoulos GS, Lopez OL, Williamson JD, Yaffe K. Depressive symptoms, vascular disease, and mild cognitive impairment: findings from the Cardiovascular Health Study. Arch Gen Psychiatry 2006;63:273-279

39. Borenstein Graves A, Mortimer JA, Bowen JD, McCormick WC, McCurry SM, Schellenberg GD, et al. Head circumference and incident Alzheimer's disease: modification by apolipoprotein E. Neurology 2001;57:1453-1460.

40. Haan MN, Shemanski L, Jagust WJ, Manolio TA, Kuller L. The role of APOE epsilon4 in modulating effects of other risk factors for cognitive decline in elderly persons. JAMA 1999;282:40-46.

41. Geda YE, Knopman DS, Mrazek DA, Jicha GA, Smith GE, Negash S, et al. Depression, apolipoprotein E genotype, and the incidence of mild cognitive impairment: a prospective cohort study. Arch Neurol 2006; 63:435-440.

42. Corsentino EA, Sawyer K, Sachs-Ericsson N, Blazer DG. Depressive symptoms moderate the influence of the apolipoproteine epsilon 4 allele on cognitive decline in a sample of community dwelling older adults. Am J Geriatr Psychiatry 2009;17:155-165.

43. Krishnan V, Nestler EJ. The molecular neurobiology of depression. Nature 2008;455:894-902.

44. Bale TL. Stress sensitivity and the development of affective disorders. Horm Behav 2006;50:529-533. 